\title{
Advance Automatic Toll Collection \& Vehicle Detection using Iot
}

\author{
Shiela David, Amrit Anupam Biswal, Sagar Pratap, Hariharan.K
}

\begin{abstract}
In our step by step life we as often as possible go through toll square.There is a blockage wastage of time as well as fuel at toll gates. To vanquish above issues, it becomes critical to quicken the method near toll court. From now on to overcome the issues saw toll court RFID based toll gathering structure is used. The planning time required by RFID Toll Collection System is extensively not exactly but manually toll amassing structure. Manually toll gathering structure in like manner prompts human botches which may incite erroneous toll aggregation. We furthermore every now and again find the opportunity to hear that the amount of endeavor at murder cases is extending well ordered. There may even be a loss of life. It's difficult to get the liable party in endeavor at homicide cases. It is seen that in case of stolen vehicle it is incredibly difficult to pursue the vehicle. It is critical to control all these above issues. Thusly, systems similarly has additional function of distinguishing the stolen vehicles and disaster cases that are enlisted. It is seen that over-troubling the vehicles may incite accident and besides hurt the boulevards. This issue is adds address for system by measuring items passing on vehicle and blame them for excess toll if it is over-trouble so they won't over-load again. Structure moreover makes portion system straightforward by making all trade. An assessment in field of usage of RFID structure is developing giant scale.
\end{abstract}

Keywords : Internet of things; IOT, Smart Roadways, digital technology, public transport problem .

\section{INTRODUCTION}

The Electronic toll collection structure is used for changing manual trade work for the customized toll social affair with RFID development. Essential objectives behind the systems are reducing the more drawn out holding up time in the toll line, diminishing illegally used toll portal section. This improves the speed and the capability of traffic stream and saves drivers' time. On account of these objectives, it decreases loss of is prepared as per journal the template. 3 . Contents of the paper are fine and satisfactory. Author (s) can make rectification in the final paper but after the final submission to the journal, rectification is not possible. fuel, usage of paper and attempts in the organization at toll court. RFID marks are provided for the customers and are investigated RFID peruse fixed at toll corners in express positions and online trades are finished as for the specified RFID name number of customers. In view of the online trade

Revised Manuscript Received on November 08, 2019.

Shiela David, CSE,Assistance professor,SRM Institute of Science and Technology, Chennai, India. Email: shielarani23@gmail.com.

Amrit Anupam Biswal, CSE, SRM Institute of Science and Technology, Chennai, India. Email: amrit.anupam60@gmail.com.

Sagar Pratap, CSE, SRM Institute of Science and Technology, Chennai, India. Email:sagarpratap04@gmail.com.

Hariharan.K, CSE, SRM Institute of Science and Technology, Chennai, India. Email:ts371527@gmail.com this structure offers straightforwardness for the whole system. From the customers point of view, web application is given.IOT Based Toll Booth head structure urges the toll corners to assemble the toll by basically swiping a card.

The endeavor involves four keys by which the customer can pick the strategy for toll amassing. At the point when the RFID mode is picked, the LCD demonstrates the message to show the RFID card. The card must be then swiped on the Card Reader. After the card is swiped, the littler scale controller: Arduino will check if the card is generous or not. If the card is genuine, by then the scaled down scale controller will check if the card has sufficient equality. The card evening out is appeared on the LCD appear. At the point when the little scale controller perceives sufficient evening out, the toll passage is opened and the vehicle is allowed to experience. We have used an IR-sensor for instance Infrared Sensor to show that the vehicle has crossed the toll entryway and the passage will be closed.

In case the card holder needs to resuscitate the card, the invigorate mode is picked. The LCD will demonstrate that the Recharge mode is picked and instruct to show the card. The card must be then swiped on the card peruser. The LCD by then shows the message to enter the restore aggregate. The customer needs to enter the aggregate and thereafter press $\mathrm{Ok}$ to get.

\section{GOAL OF THE TOPIC}

The system arranged is direct and gives customized toll gathering using Image Dealing with. For the customer, there is web application similarly as android application. The customer needs to enlist and by then after the individual can buy tickets for different toll courts with different vehicles. Getting of tickets is done sitting at home. One can without a lot of a stretch drop the ticket, if he doesn't wish to travel. Customer's record similarly keeps up the history for the as of late bought tickets. The customer can even download the ticket from it. For the customers, ticket can be saved using web application or android application. Customer has the plausibility to attempt to incorporate different cars. The Admin side of the structure contains a web app in which chairman can regulate toll courts. Supervising Toll squares consolidate including new tolls when new toll court are presented on any avenues, changing the toll totals accepting any and report age. Right when the User books the ticket for any toll square, portion is done by Instamojo PaymentEntryway. There is a wallet for each customer with the objective that the total will be saved in it and will be deducted exactly when the customer touches base at the toll So the customer can even use wallet total for obtaining some other ticket. 


\section{Advance Automatic Toll Collection \& Vehicle Detection using Iot}

After the successful portion, the customer will get a SMS communicating his ticket id. In the wake of having obtained the ticket, when vehicle arrives at near the toll square, the camera fixed there recognizes the vehicle's number plate and checks for its ticket in database. If the customer has procured the ticket, prevention will be opened using IR sensors set near the toll court. The camera presented at the toll square will distinguish the vehicle and subsequently remove the vehicle's number through Raspberry Pi using Image Processing counts. On productive climax of affirming the ticket, the prevention will be opened and in the wake of crossing point the toll, another IR sensor will recognize the vehicle and the deterrent will be closed.

\section{A. Further Enhancement}

- Changing the travelling patterns.

- Improvement in public transport and traffic control.

- Reduction in congestion leads to better environment.

- Generation of revenue.

- Increses safety and works smoothly.

\section{IMPLEMENTATION}

This document gives the unraveled methodology to explorers for paying the tolls by making them modernized and besides gives intimation on vehicle. All of these activities are passed on using single RFID mark likewise saves the undertakings of passing on money as well as records physically. The RFID Readers mounted near toll corner will examine the paid early RFID marks fixed on thevehicles windshield and normally specific entirety will be perceived. Since all the vehicle enrollment ID is associated with customer account, toll can be deducted from the record bank clearly. Right when vehicle gets stolen the owner registers complaint on the site with its enlistment ID and unique RFID name number. By and by when stolen vehicle passes by the toll court, the mark fixed on it is facilitated for the stolen Vehicles tag in the database at the toll slow down. The vehicle sitting above the traffic sign will be distinguished by the RFID peruses fixed at sign crossing point and will be educated to the traffic police. This should be conceivable capably and exceptional precision. Vehicle going above speed purpose of control can be pursued $100 \%$ precision. This model proposed gives an idea, structure and execution of a web application utilizing the vehicle toll installment. The structure and execution model infer utilization of an IoT gadget which starts vehicle toll installments solicitation considering web application's web administration capacities.

- First of all, raspberry pi is booted, python program is begun, where the GUI will be appeared for camera and the current advancing method of the program will be appeared.

- As soon as, the Infrared Sensor (IR-Sensor) get input, it gets the image and with help of Cloud API of OpenALPR number plate is seen and JSON string is returned,

which is moreover taken care of by raspberry pi.

- After treatment of JSON string the number plate is affirmed with joined database, to check despite whether ticket is saved or not, again the JSON string is returned for server.

- If the ticket is held, by then with help raspberry pi servo motor is controlled and entryway is opened.Close to the piece of the course of action is another IR-sensor which perceives the vehicle.
- Once the vehicle is perceived, raspberry send sign to servo motor to close the entryway.At whatever point got picture fails to see the number or imperfect number is seen a talk box will explode with the objective that manager can enter the correct License plate.
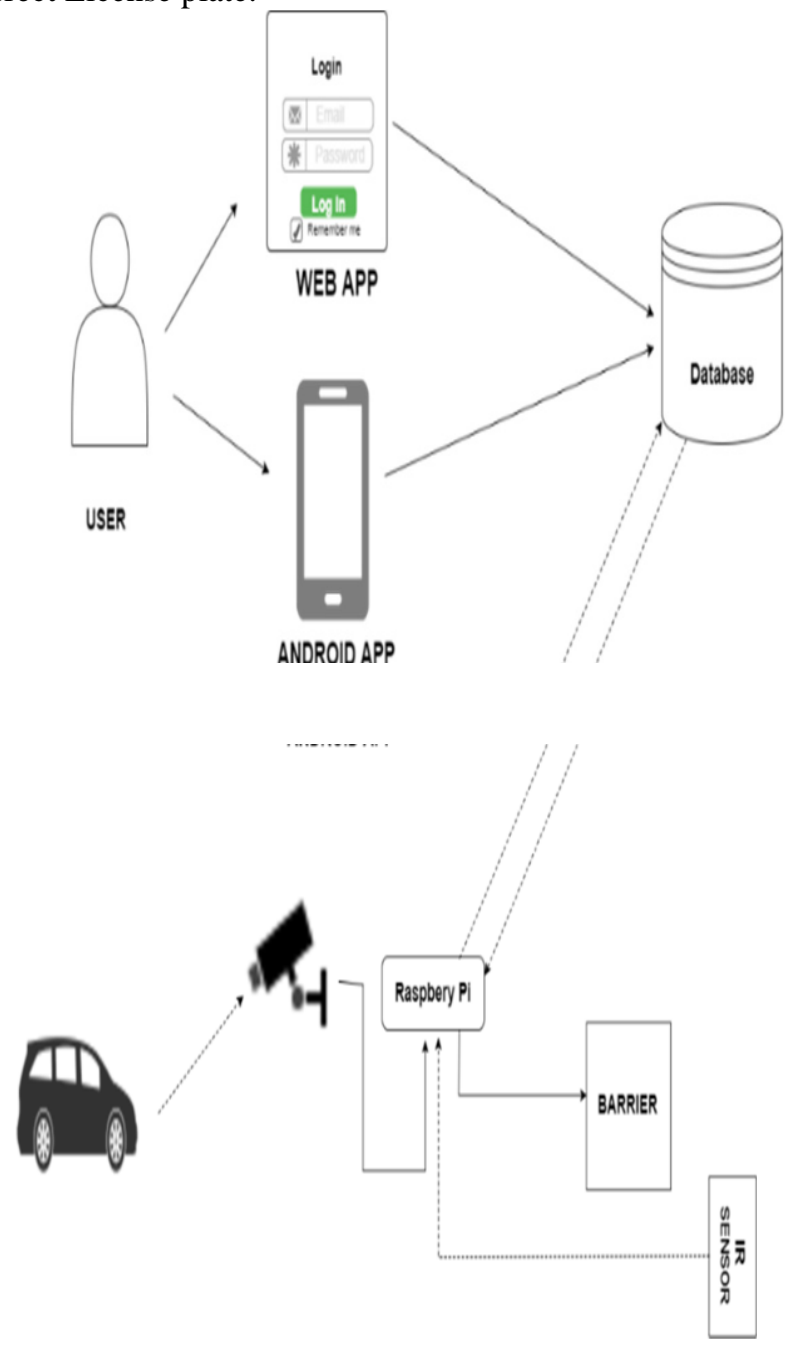

\section{GEAR PLAN FOR THE SYSTEM : -}

A.Arduino Uno:

Arduino Uno is introduced board used in our system. This microcontroller used in our structure is AT mega328P.Arduino Uno is an open source hardware and programming for architects. It is on a very basic level easy to code and easy to use. It is used when same program is to be performed under settled circles. Arduino is related with Computer join at toll corner.

\section{B. Wi-Fi Technology:}

$\mathrm{Wi}-\mathrm{Fi}$ is an area development that empowers an electronic device to share in PC frameworks organization that uses 2.4 $\mathrm{GHz}$ UHF and $5 \mathrm{GHz}$ SHF ISM radio gatherings. Various devices can use $\mathrm{Wi}-\mathrm{Fi}$, for instance PCs, PC game consoles, Smartphone's, automated cameras, tabletPCs and automated sound players. Wi-Fi is a radio repeat (RF) assurance for long-broaden point to point and point to multipoint voice and data move. These can be connected with a framework resource for instance, the Internet by methods for a remote framework get to point. Such a path (or hotspot) has a range of around 20 meters (66 feet) inside and a progressively noticeable keep running

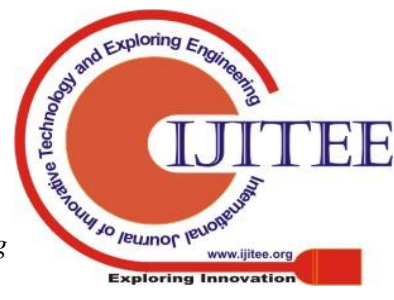


outside. Hotspot consideration can contain an zone as meager as a lone live with dividers that square radio waves, or as colossal gives similar number of square kilometers achieved by using different covering access centers.

\section{LCD:}

A $16 \times 2$ LCD suggests that it can demonstrate 16 characters per single line and this way there are 2 such lines. In this LCD each character is appeared in $5 \times 7$ pixel structure. This LCD has two registers, to be explicit, Command and data. The request register stores the bearings given to LCD. This request is a direction given to LCD to do a predefined task like instating it, clearing the screens, setting the cursor position, controlling exhibit, etc. This data register stores all the data to be appeared on the LCD. This data has the ASCII estimation of the character that is to be appeared on the LCD.

\section{A. Programming usage for the framework: -}

To achieve the framework, the picking of Programming is significant. The Embedded $\mathrm{C}$ is used to execute the framework. The $\mathrm{C}$ language is acquainted with huge numbers of the clients and appropriate for GUI structure.

\section{B.Implementation of $C$ : -}

Implementation of $\mathrm{C}$ is the augmentation for the programming language $\mathrm{C}$ to help inserted processors, empowering versatile and capable application programming for inserted framework. An inserted framework is the blend of PC equipment as well as programming, either fixed in ability. $\mathrm{C}$ language has little, more straight forward to learn, get the programs and investigate them. $\mathrm{C}$ compilers are accessible to all practically implanted gadgets and it is advantageous for all clients.

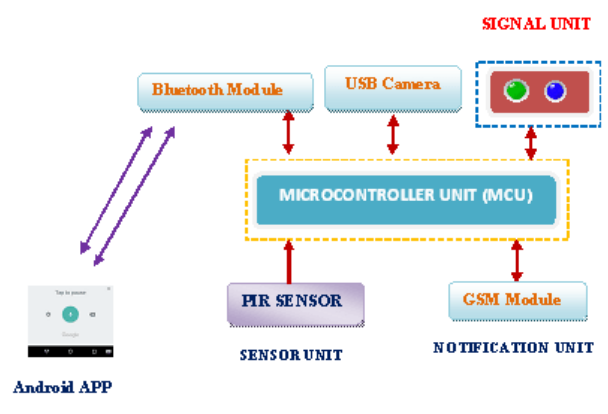

\section{RELATED WORKS: -}

For the clients, ticket can be spared utilizing web application or android application. Client has the believability to endeavor to consolidate various vehicles. The Admin side of the structure contains a webapp in which administrator can control toll courts. Managing Toll squares solidify including new tolls when new toll court are displayed on any roads, changing the toll aggregates tolerating any and report age. Right when the User books the ticket for any toll square, parcel is finished by Instamojo Payment Gateway . There is a wallet for every client with the target that the complete will be spared in it and will be deducted precisely when the client gets in contact at the toll. So the client can even utilize wallet aggregate for getting some other ticket. After the effective part, the client will get a SMS conveying his ticket id. In the wake of having gotten the ticket, when vehicle touches base at close to the toll square, the camera fixed there perceives the vehicle's number plate and checks for its ticket in database. In the event that the client has obtained the ticket, aversion will be opened utilizing IR sensors set close to the toll court. The camera exhibited at the toll square will recognize the vehicle and along these lines evacuate the vehicle's number through Raspberry $\mathrm{Pi}$ utilizing Image Processing checks. On profitable peak of avowing the ticket, the anticipation will be opened and in the wake of intersection point the toll, another IR sensor will perceive the vehicle and the hindrance will be shut.

\section{A. Customary Systems: -}

At present the regular toll squares are working physically. This technique for toll gathering information is tedious. The regular method for gathering the toll from the vehicle proprietors or the drivers is to stop the vehicle at the Toll Plaza and after that pay the sum to the toll authority by the side of the toll corner, after which the entry way is opened either precisely or electronically for the driver to get past the toll station. These stops, brings about wastage of both fuel and time. One more issue is that one needs to deal with money and even sit tight for getting the change. In the wake of making good on the toll government expense, a receipt is given which one needs to save when the ticket obtained is an arrival ticket. On a normal every vehicle that goes through the toll court needs to hold up 5.0 hours, keeping their motors turned on. This figure is stunning, as though on a normal we take 200 vehicles pass through the toll square every day, at that point yearly 72000 vehicles are passed through the toll court, so for every year 72000 vehicles sits tight for 5.0 hours keeping their motors on and in this manner supporting contamination also, squandering fuel and cash. The inexact $\mathrm{CO} 2$ outflow per liter of diesel fuel is $2.68 \mathrm{~kg}$, and for petroleum it is roughly $2.31 \mathrm{~kg}$. LPG delivers around $1.51 \mathrm{~kg}$ per liter which results in contamination.

\section{B. Electronic Toll Collection System: -}

Electronic Toll Collection System utilizes Radio Frequency Identification (RFID) technology. A RFID tag is mounted for each vehicle with unique ID. This ID is invisible on tags, it contains all the information about the vehicle and owner. When vehicle reaches at toll plaza tag emits the radio wave signal. RFID reader receives the signal from tag, decode that signal and send to the ARM controller. The controller will display the vehicle number and amount on LCD. Microcontroller is interfaced with computer to collect the vehicle data through serial port for future use. When accessed form database, shows all the vehicle details on computer screen such as ID, vehicle number, date and time. Microcontroller checks the balance, if sufficient balance is there, it deducts predefined amount from prepaid account and updates the balance in that account.

\section{RESULT}

These associations had either no data or central learning of tolling when they entered the tolling business, Ministry of Road Transport specialists illustrated. There is dynamic affirmation tolling is a specific and complex development and many changed factors contribute towards its flourishing. According to a disagreeable examination, toll pilferage on not well supervised courts can be as high as 25 percent.

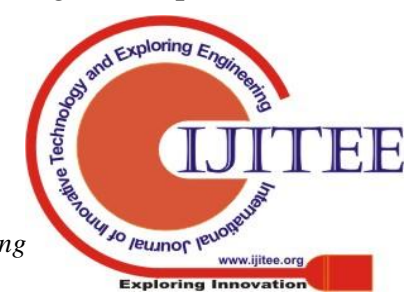




\section{Advance Automatic Toll Collection \& Vehicle Detection using Iot}

Undoubtedly, even a short lived disillusionment of toll IT system can realize broad toll pilferages. Clients treat roads as an open nice where the organization should be without given by the legislature. With wide-spread improvement of roads, causing critical harm reroute has transformed into a standard practice by most road customers. In a colossal number of concession understandings, there are no shields like check squares. As such, to avoid loss of toll gatherings, picking the correct territory for the court winds up essential.

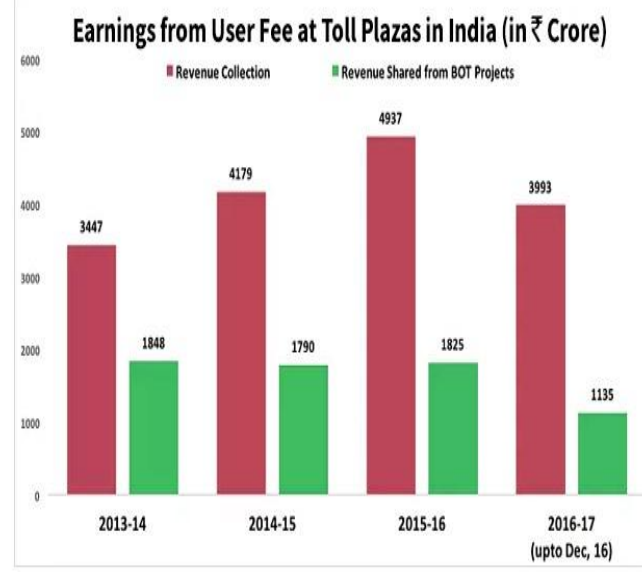

\section{CONCLUSION}

The automated toll gathering system will help in immensely reduce the time required to wrap up

the technique of issuing toll receipts and enable the whole system to be swifter. The structure in addition

clears out likelihood of any kind of human misstep that might be possible with the customary toll collection structures. There will be unprecedented diminishing in carbon releases similarly as fuel use as the vehicle needs not to stop at the toll courts. This structure thusly clears way to a cleaner, greener and swifter methodology when appeared differently in relation to the present structure. RFID is an exceptionally steady and dependable innovation. The RFID Automatic toll door framework can consequently identify the characters of the vehicles, perusing things moving and following of the vehicles should be possible precisely utilizing RFID. From the start the framework may appear in all respects expensive yet following a time of the framework implantation high advantages will be gotten as it will prompt lower operational expenses and expanded income age. It not just diminishes the traffic related issues of the nation yet additionally demonstrates to be a noteworthy innovative improvement in the country which is the need of great importance as various nations everywhere all over the world are ending up in fact solid. In this paper, we have displayed the usage of Wi-Fi innovation for the utilization of toll charge framework. Wi-Fi toll gathering stations enables the traffic to stream constantly and vehicle have been abstained from ceasing and beginning once more. This in blend with decreased fuel utilization has beneficial outcome on condition for example contamination made will be least. Actualizing the Wi-Fi innovation is additionally not all that expensive. Man power and money dangers are additionally diminished to least. Besides, just at least traffic disturbance is caused during establishment. The framework too expands security, as bottlenecks and long lines are maintained a strategic distance from. Society and business network additionally are gained from the framework as this brings about quicker transportation. The framework is practical, efficient and simple to introduce which advantages the administrator just as client. IoT based toll stall checking framework is a Arduino based toll gathering framework. The outcomes gotten from working have demonstrated that the framework execution is very solid. The framework has effectively beat the deficiencies of the current framework by diminishing the labor at the toll stall. It gives simple method for toll gathering what's more, support of the data.

\section{REFERENCE}

1. N. Jeevagan, P. Santosh, R. Berlia, S. Kandoi, "RFID Based Vehicle Identification " IEEE Global Humanitarian Technology Conference 2018.

2. R. Kalantri, A. Parekar, A. Mohite, R. Kankapurkar, "RFID based toll collection system," International Journal of Computer Science and Information Technologies, Vol. 5 (2) 2018.

3. R.B. Takbhate,S.D. Chavan "Automated Toll Booth System," International Journal of Research Studies in Computer Science and Engineering, Vol. 1 (3), July2018 .

4. T.Aphale, R. Chaudhari, J. Bansod “Automated Toll Plaza Using RFID and GSM" International Journal on Recent and Innovation Trends in Computing and Communication Volume: 2 Issue: 9, September 2018

5. G.K. Andurkar, V.R. Ramteke,'Smart Highway Electronic Toll Collection System," International Journal of Innovative Research in Computer and Communication EngineeringVol. 3, Issue 5, May 2018

6. M.Rajeswari ,S.Chandana,D.VPruthvi, SarithaS.P,Ramya "Collision Detection And Avoidance Using Intelligent Vehicle Communication Protocol," National Conference on Recent Advances in Information \& Communication Engineering (NCRAICE-2018)

7. R.Aishvarya, S.Poornima, K.Pradeepa, T.Subashini4, K.P.Lavanya "Automatic and Effective Tracking of Hit \& Run Misbehavior Driver with Emergency Ambulance Support,'International Journal of Advanced Research in Electrical, Electronics and Instrumentation Engineering Vol. 5, Issue 3, March 2018.

\section{AUTHORS PROFILE}

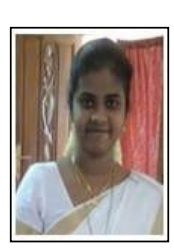

Shiela David, She is working as Assistant professor in computer science Engineering department in SRM Institute of Science and Technology, chennai. She did her b.tech degree in from Anna University,Chennai.She is having wide area of interest in the field of Technical department. She has more than 18 years of experience at the time of writing this paper. He has served at different positions in various universities and Engineering Colleges. Her area of interests includes Computer Science, Data Science

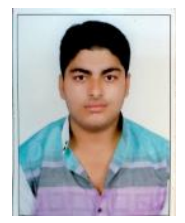

Amrit Anupam Biswal, $\mathrm{He}$ is currently pursuing B.Tech degree in Computer Science from SRM Institute of Science and Technology,Chennai, India. His Research interests include Power electronic, Solar system, IOT automation Circuit designing.He is also researching about On the security and privacy of internet of things architectures and systems. In Secure Internet of Things a book is published before but it's a group work

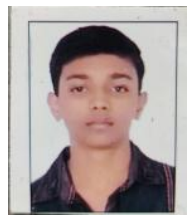

Sagar Pratap, He is currently pursuing B.Tech degree in Computer Science from SRM Institute of Science and Technology,Chennai, India.His Research interests include Web Mining, Internet of Things, and Deep Learning. active research areas include cloud computing, big data analytics, evolutionary algorithms and software engineering.

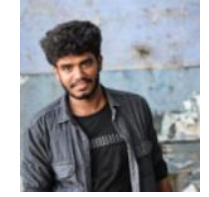

Hariharan .K , He is currently pursuing B.Tech degree in Computer Science from SRM Institute of Science and Technology,Chennai, India. His Research interests include electric sensors and Human Development Resources using IOT ,Computer

Networks ,Wireless Communication, 